\title{
DESAIN E-COMMERCE USAHA MIKRO KECIL MENENGAH (UMKM) BENI SCROLL ART BERBASIS ANDROID
}

\author{
(DESIGN OF BENI SCROLL ART E-COMMERCE Micro, Small and Medium Enterprises \\ (MSMES) BASED ON ANDROID)
}

\author{
Triana Sri Gunarti ${ }^{1 *}$, Baibul Tujni ${ }^{2}$, Imam Solikin ${ }^{3}$ \\ Universitas Terbuka ${ }^{1}$, Universitas Bina Darma ${ }^{2,3}$ \\ Emailtrianasg@ecampus.ut.ac.id ${ }^{1 *}, \underline{\text { baibul@binadarma.ac.id }{ }^{2}}, \underline{\text { imamsolikin@binadarma.ac.id }{ }^{3}}$
}

\begin{abstract}
ABTRACT
Micro, Small and Medium Enterprises (MSMEs) are productive businesses owned by individuals and business entities that have met the criteria as micro-enterprises. Marketing and sales that occur in Beni Scroll Art's Micro, Small and Medium Enterprises, apart from directly meeting customers, are also carried out using the website. At present, many Micro, Small and Medium Enterprises are already using Android-based technology because they are more familiar, Micro, Small and Medium Enterprises that have not used Android-based information technology are that their sales have decreased and can even cause businesses to close. Solutions to the problems of Beni Srcoll Art's Micro, Small and Medium Enterprises by developing an Android-based marketing and sales transaction system. The development method used for android application development is a prototype with the following steps: communication, quick plan, modeling and quick design, quick design, construction of prototype, and deployment delivery and feedback. The purpose of this development is to facilitate marketing and sales transactions and to increase sales. The results of the research are Android-based e-commerce on Beni Scroll Art Micro, Small and Medium Enterprises.
\end{abstract}

Keywords: UMKM, e-commerce, android, prototype

\section{Pendahuluan}

Teknologi informasi berbasis android merupakan teknologi informasi yang mengalami kemajuan sangat pesat di Indonesia. Teknologi informasi tersebut hampir digunakan oleh seluruh kalangan masyarakat untuk kebutuhan sehari-hari bahkan digunakan untuk bisnis. Dalam dunia bisnis teknologi informasi berbasis android tersebut digunakan untuk meningkatkan penjualan dan kemajuan usahanya. Usaha Mikro Kecil Menengah (UMKM) juga banyak yang sudah menggunakan teknologi tersebut, untuk menajukan usahanya.

"UMKM (Usaha Mikro Kecil Menengah) merupakan usaha produktif yang dimiliki perorangan maupun badan usaha yang telah memenuhi kriteria sebagai usaha mikro". "UMKM merupakan salah satu faktor yang mempengaruhi pertumbuhan ekonomi di Indonesia". Adapun usaha-usaha yang ada pada UMKM berupa kerajinan tangan seperti membuat piala kayu, miniatur kayu, angka dari kayu, huruf dari kayu, nampan dari kayu, asbak dari kayu dan kerajian tangan lainnya.

Objek pada penelitian ini adalah UMKM Beni Scroll Art yang merupakan UMKM yang bergerak dalam bidang kerajinan tangan. Pemasaran dan penjualan yang terjadi pada UMKM Beni Scroll Art saat ini selain secara langsung bertemu pelanggan juga dilakukan dengan menggunakan website. Saat ini UMKM banyak yang sudah menggunakan teknologi berbasis android karana lebih familiar dimasyarakat sehingga lebih cepat dalam meninggakan penjualan dan mempermudah dalam pemasaran dan transaksi penjualan. Dampak yang didapat oleh UMKM yang belum menggunakan teknologi informasi berbasis android adalah penjualannya mengalami penurunan bahkan bisa menyebabkan usaha tutup. "Hasil survey berkerja sama dengan Teknopreneur mengemukakan, penetrasi pemakai internet tahun 2017, lebih dari 54,7 persen atau sekitar 143,36 juta orang yang terhubung dengan internet, dari total populasi penduduk indonesia 262 juta orang, pada survey yang sama pada tahun 2016 ke tahun 2017", menurut Henry K Soemartono, Sekretaris Jendral Asosiasi Penyelenggara Jasa Internet Indonesia (APJII) (APJII, 2018).

Solusi dari permasalah UMKM Beni Srcoll Art dengan melakukan pengembangan dalam sistem pemasaran dan transaksi penjualan berbasis android. Tujauan dari pengembangan ini, untuk mempermudah pemasaran dan transaksi penjualan serta untuk meningkatkan penjualan. Metode 


\section{Seminar Ilmiah Sistem Informasi Manajemen dan Akuntansi (SISIMA) 2021}

pengembangan yang digunakan untuk pengembangan aplikasi android adalah prototype dengan langkah-langkah sebagai berikut communication, quick plan, modelling and quick design, quick design, construction of prototype, and deployment delivery and feedback. Hasil dari penelitian ini adalah menghasilkan e-commerce berbasis android pada UMKM Beni Scroll Art.

\section{Tinjauan pustaka}

A. Usaha Mickro Kecil Menengah (UMKM)

"UMKM menurut Undang-Undang No. 20 Tahun 2008 tentang Usaha Mikro, Kecil dan Menengah Bab 1 Pasal 1: Usaha mikro adalah usaha produktif milik orang perorangan dan atau badan usaha perorangan yang memenuhi kriteria usaha mikro. Usaha kecil adalah usaha produktif yang berdiri sendiri, yang dilakukan oleh perseorangan atau badan usaha bukan merupakan anak cabang perusahaan yang dimiliki, dikuasai, atau menjadi bagian baik langsung maupun tidak langsung dari usaha menengah atau besar yang memenuhi kriteria usaha kecil. Usaha menengah adalah usaha ekonomi produktif yang berdiri sendiri, yang dilakukan oleh orang perorangan atau badan usaha yang bukan merupakan anak perusahaan atau cabang perusahaan yang dimiliki, dikuasai, atau menjadi bagian baik langsung maupun tidak langsung dengan Usaha kecil atau Usaha besar dengan jumlah kekayaan bersih atau hasil penjualan tahunan."

"UMKM menurut Kementrian Koperasi dan UMKM dalam Aufar (2014:8): Usaha Kecil (UK), termasuk usaha Mikro (UMI) adalah entitas usaha yang mempunyai kekayaan bersih paling banyak Rp. 200.000.000, tidak termasuk tanah dan bangunan tempat usaha dan memiliki penjualan tahunan paling banyak Rp. 1.000.000.000. Sementara itu, Usaha Menengah (UM) merupakan entitas usaha milik warga negara Indonesia yang memiliki kekayaan bersih lebih besar dari Rp. 200.000 .000 s.d. Rp. 10.000 .000 tidak termasuk tanah dan bangunan."

"UMKM menurut Bank Indonesia dalam Aufar (2014:9): Usaha kecil adalah usaha produktif milik warga negara Indonesia, yang berbentuk badan usaha orang perorangan, badan usaha yang tidak berbadan hukum, atau badan usaha berbadan hukum seperti koperasi; bukan merupakan anak perusahaan atau cabang yang dimiliki, dikuasai atau berafiliasi, baik langsung maupun tidak langsung dengan usaha menengah atau besar. Memiliki kekayaan bersih paling banyak Rp. 200.000.000, tidak termasuk tanah dan bangunan atau memiliki hasil penjualan paling banyak Rp. 200.000.000 per tahun, sedangkan usaha menangah, merupakan usaha yang memiliki kriteria aset tetapnya dengan besaran yang dibedakan antara industry manufaktur (Rp. 200.000.000 s.d. Rp. 500.000.000) dan non manufaktur (Rp. 200.000 .000 s.d. Rp.600.000.000).”

\section{B. Android}

"Android adalah software untuk perangkat mobile yang mencakup sistem operasi, middleware dan aplikasi kunci. Pengembangan aplikasi pada platform Android menggunakan bahasa pemrograman Java. Serangkaian aplikasi inti Android antara lain klien email, program SMS, kalender, peta, browser, kontak, dan lain-lain. Menurut Nasruddin Safaat h (Pemrograman aplikasi mobile smartphone dan tablet PC berbasis android 2012:1) android adalah sebuah sistem operasi pada handphone yang bersifat terbuka dan berbasis pada sistem operasi Linux. Android bisa digunakan oleh setiap orang yang ingin menggunakannya pada perangkat mereka."

\section{Penjualan}

"Penjualan menurut Winardi (2005:26) adalah sebagai berikut: Penjualan adalah berkumpulnya seorang pembeli dan penjual dengan tujuan melaksanakan tukar menukar barang dan jasa berdasarkan pertimbangan yang berharga misalnya pertimbangan uang. Penjualan menurut Thamrin Abdullah dan Francis Tantri (2016:3) Penjualan adalah bagian dari promosi dan promosi adalah salah satu bagian dari keseluruhan sistem pemasaran.”

D. Penelitian Sebelumnya

"Penelitian yang digunakan untuk referensi dalam penelitian ini antara lain: 1) Aplikasi penjualan online berbasis android (studi kasus: di Toko Hoax Merch), 2) Perancangan dan implementasi e- 


\section{Seminar Ilmiah Sistem Informasi Manajemen dan Akuntansi (SISIMA) 2021}

commerce untuk penjualan baju online berbasis android, 3) Rancang bangun aplikasi pemesanan dan penjualan berbasis web dan android pada Toko YT. Wall Interior, 4) Penerapan teknologi Augmented reality pada aplikasi katalog rumah berbasis android, 5) Perancangan aplikasi penjualan batik berbasis android (Studi kasus di Batik Puspa Kencana, Laweyan, Solo), 6) Aplikasi penjualan shoes pada toko Destina berbasis android (Studi Kasus: Toko Destina)."

\section{Metode penelitian}

A. Metode Pengembangan Aplikasi Android

Metode yang digunakan dalam pengembangan aplikasi android adalah metode Prototype (Pressman: 2010). "Prototype adalah sebuah metode perancangan software yang banyak digunakan pengembang agar dapat saling berinteraksi dengan pelangan selama proses pembuatan sistem". Metode ini memiliki 5 langkah yang saling terkait atau mempengaruhi, untuk langkah-langkah dapat dilihat pada gambar 1 .

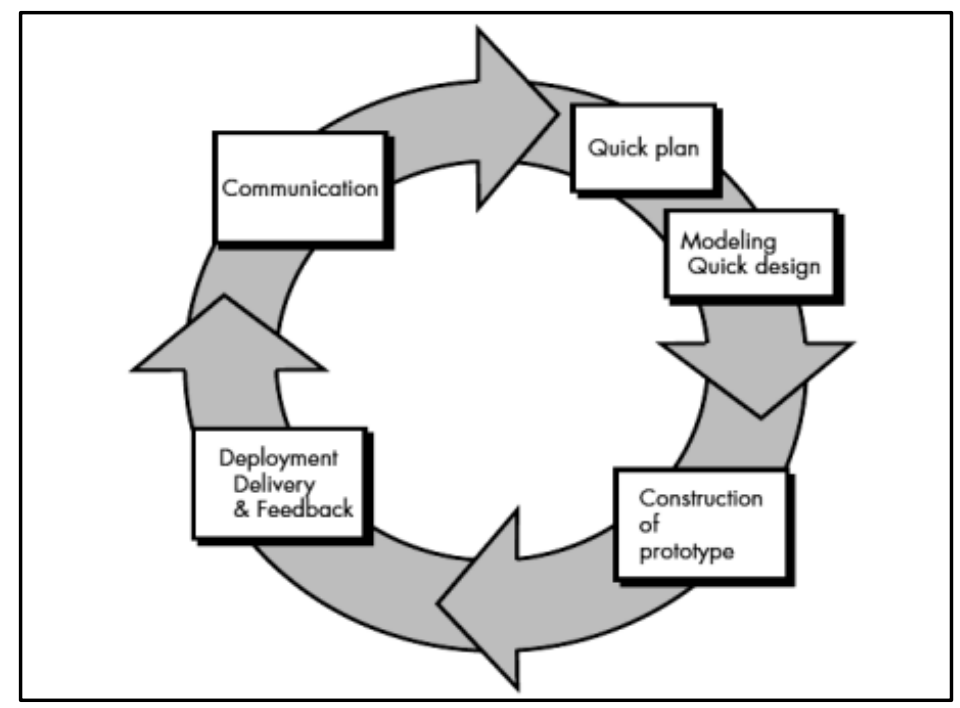

Gambar 1. Metode Prototype, (Pressman: 2010)

Penjelasan Langkah-langkah dari model prototype yang di gambar 1, yaitu:

1. Communication / Komunikasi Tim perancang perangkat lunak melakukan pertemuan dengan para stakeholder UMKM Beni Scroll Art untuk menentukan kebutuhan e-commerce berbasis android yang akan dibangun yang saat itu diketahui dan untuk menggambarkan areaarea dimana definisi lebih jauh untuk iterasi selanjutnya.

2. Quick Plan / Perencanaan Secara Cepat, dalam perencanaan e-commerce berbasis android pada UMKM Beni Scroll Art serta pembuatan prototype dilakukan secara cepat. Setelah itu dilakukan pemodelan dalam bentuk rancangan cepat.

3. Quick Design / Model Rancangan Cepat, pada tahap ini dilakukan pemodelan perencanaan ditahap sebelumnya dengan menggunakan pemodelan terstrukturdalam bentuk DFD (Data Flow Diagram), ERD (Entity Relationship Diagram) dan Flowchart untuk menggambarkan analisis dan desain $e$ commerce berbasis android pada UMKM Beni Scroll Art.

4. Construction of Prototype / Pembuatan Prototype, dalam pembuatan rancangan cepat berdasarkan pada representasi aspek-aspek perangkat lunak yang akan terlihat oleh para end user (merancangan interface e-commerce berbasis android pada UMKM beni Scroll Art)..

5. Deployment Deliery \& Feedback / Penyerahan Dan Memberikan Umpan Balik Terhadap, pengembangan Prototype kemudian diserahkan kepada para stakeholder untuk mengevaluasi prototype yang telah dibuat sebelumnya dan memberikan umpan-balik yang digunakan untuk memperbaiki spesifikasi kebutuhan. Iterasi terjadi saat pengembang melakukan perbaikan terhadap prototype tersebut.

B. Metode Pengumpulan Data 


\section{Seminar Ilmiah Sistem Informasi Manajemen dan Akuntansi (SISIMA) 2021

"Interview, teknik ini ialah pengumpulan data yang datanya diperoleh dari responden secara mendalam dan berkaitan dengan penelitian untuk menemukan suatu permasalahan serta pontensi yang harus diteliti (Sugiyono: 2013)". Interview ditunjukan kepada UMKM Beni Scroll Art.untuk memperoleh data mengenai, transaksi penjualan, data hasil produksi dari UMKM Beni Scroll Art, data jangkauan wilayah pembeli.

"Observasi, teknik ini merupakan pengumpulan data melalui pengamatan secara langsung atau melihat langsung tanpa menggunakan bantuan alat standar lain untuk tujuan tersebut (Nazir: 2014)". Observasi langsung ke tempat Produksi UMKM Beni Scroll Art, hasil observasi mengamati proses produksi dari UMKM Beni Scroll Art, dan prosesn transaksi penjualan dari UMKM Beni Scroll Art.

\section{Hasil dan pembahasan}

\section{A. Peracangan Flowchart e-commerce Beni Scroll Art}

Peracangan flowchart e-commerce berbasis android pada UMKM Beni Scroll Art, menggambarkan alur sistem dari aplikasi yang dibangun. Flowchart ecommerce berbasis android pada UMKM Beni Scroll Art bisa dilihat pada gambar 1 .

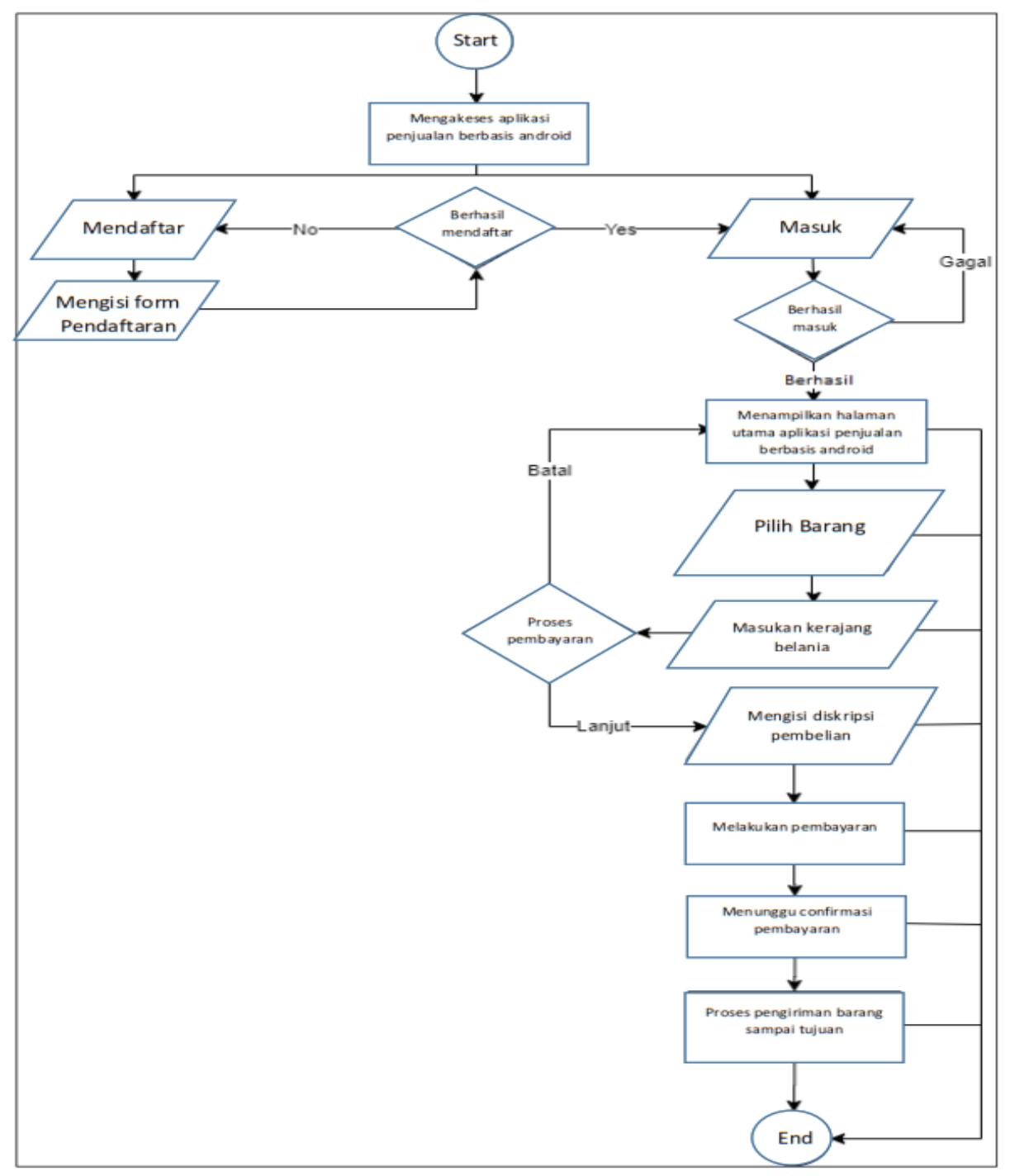

Gambar 1. Flowchart e-commerce UMKM Beni Scroll Art

Keterangan: 


\section{Seminar Ilmiah Sistem Informasi Manajemen dan Akuntansi (SISIMA) 2021}

Pelanggan harus mendaftar untuk mempunyai akun sebelum melakukan pembelian pada UMKM Beni Scroll Art. Pelanggan yang sudah mempunyai akun bisa dapat login sesuai dengan username yang didaftarkan pada proses pendaftran. Pelanggan yang dapat login bisa melakukan aktifitas pembelian barang pada UMKM Beni Scroll Art. Pelanggan menetukan barang yang diinginkan, pada kerangjang belanjan pelanggan dapat membatalkan barng yang tidak diinginkan dan juga bisa menambah barang. Selanjutnya pelanggan dapat melihat rincian dari barang yang akan dibeli. Untuk proses terkhir adalah proses pembayaran sampai proses pengiriman barang.

B. Perancangan e-commerce berbasis Android

Peracangan login yang dapat dilihat pada gambar 2. ini merupakan rancangan untuk masuk ke akun pelanggan menggunakan hak akses sesuai dengan username ketika pelanggan mendaftar.

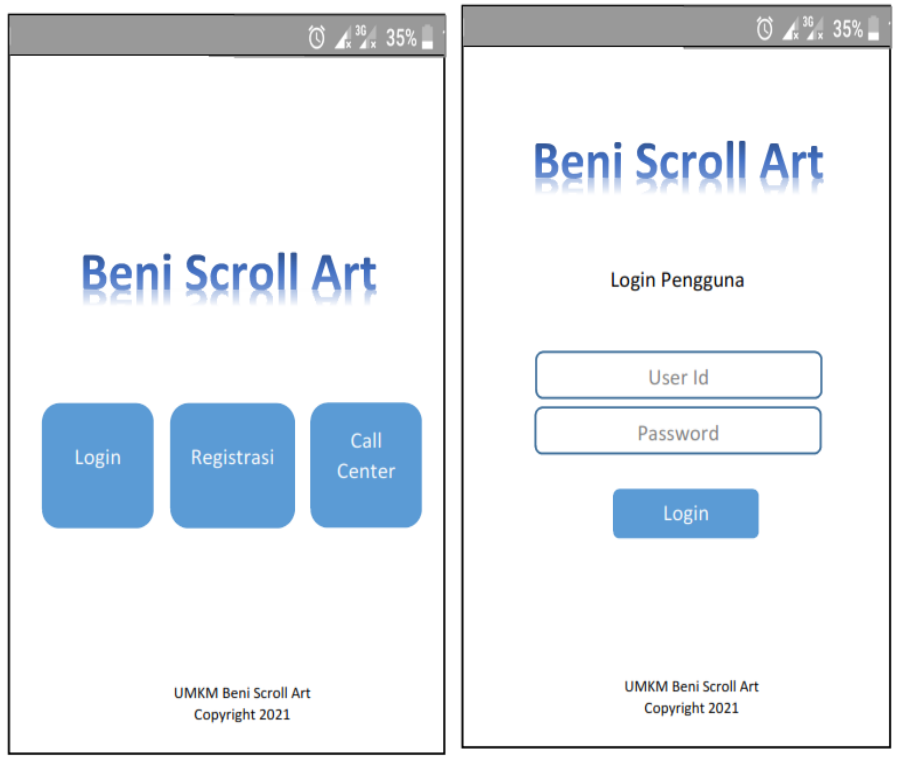

Gambar 2. Rancangan login

Rancangan product digunakan untuk menampilan barang-barang kerajinan tangan yang siap dijualan pada UMKM Beni Scroll Art, racangan product dapat dilihat pada gambar 3

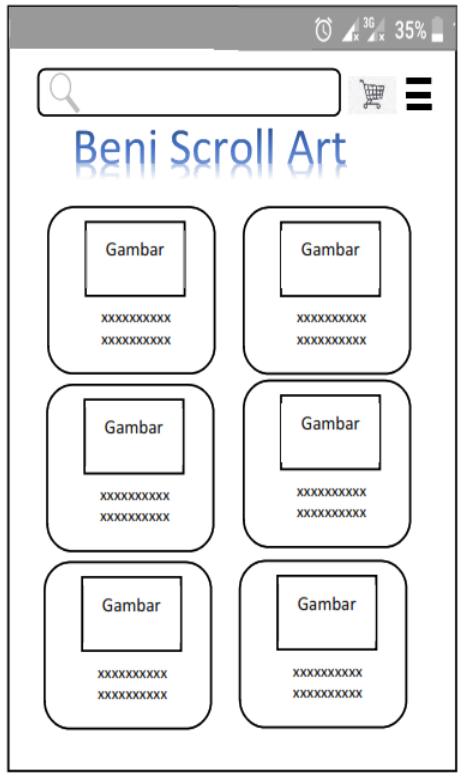

Gambar 3. Rancangan product 


\section{Seminar Ilmiah Sistem Informasi Manajemen dan Akuntansi (SISIMA) 2021}

Pada racangan rincian product menampilkan detail setiap barang kerajinan tangan UMKM Beni Scroll Art, rancangan rincian product dapat dilihat pada gambar 4.

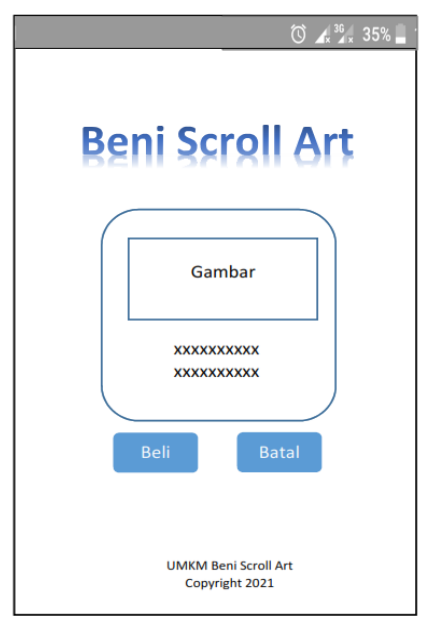

Gambar 4. Rancangan rincian product

Rancangan cart digunakan dalam rincian barang yang akan dibeli, rancangan cart dapat dilihat pada gambar 5.

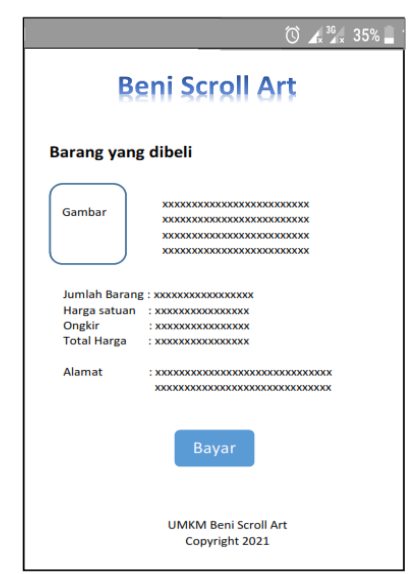

Gambar 5. Rancangan cart

Rancangan pembayaran digunakan untuk menampilkan jumlah total harga barang yang dibeli pada UMKM Beni Scroll Art dan harus dibayar, rancngan pembayran dapat dilihat pada gambar 6 .

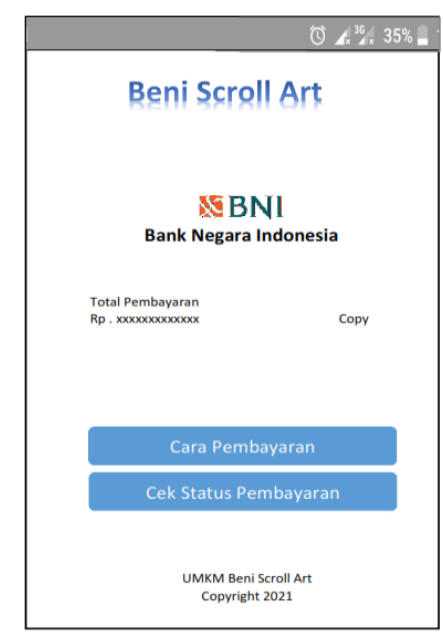




\title{
Seminar Ilmiah Sistem Informasi Manajemen dan Akuntansi (SISIMA) 2021
}

\author{
Gambar 6. Rancngan pembayaran
}

\section{Kesimpulan}

Kesimpulan yang didapat berdasarkan pembahasan dari penelitian adalah: menghasilkan perancangan e-commerce berbasis android pada UMKM Beni Scroll Art untuk meningkatkan penjualan dan pemperluas transaksi penjualan, sert mempermudah transaksi penjualan pada UMKM Beni Scroll Art.

\section{REFERENSI}

Abdullah, T., \& Tantri, F. (2012). Manajemen pemasaran. Depok: PT Raja Grafindo Persada.

Dikanata, D., \& Wati, R. (2018). APLIKASI PENJUALAN SHOES PADA TOKO DESTINA BERBASIS ANDROID (Studi Kasus: Toko Destina). PROCIDING KMSI, 6(1), 19-24.

https://www.ubaya.ac.id/2018/content/articles_detail/7/Android--Sistem-Operasi-padaSmartphone.html\#: :text=Android\%20adalah\%20software\%20untuk\%20perangkat,kontak\% 2C\%20dan\%20lain\%2Dlain. (diakses 10/02/2021).

Kusuma, A. P., \& Prasetya, K. A. (2017). Perancangan dan implementasi e-commerce untuk penjualan baju online berbasis android. ANTIVIRUS: Jurnal Ilmiah Teknik Informatika, 11(1).

Marjito, M., \& Tesaria, G. (2016). Aplikasi penjualan online berbasis android (studi kasus: di toko hoax merch). Jurnal Computech \& Bisnis, 10(1), 40-49.

Nazir, M. (2014). Metode Penelitian (Research Method). Bogor: Ghalia Indonesia.

M. P. K. Sugiyono, 2013. Kualitatif, dan Kombinasi (Mixed Methods). Bandung Alf.

Sitepu, A. I. B., \& Tanjung, D. Y. H. (2020). Rancang Bangun Aplikasi Pemesanan dan Penjualan Berbasis Web dan Android pada Toko YT. Wall Interior. Jurnal Mahasiswa Fakultas Teknik dan Ilmu Komputer, 1(1), 816-828.

Pressman, R. S. (2005). Software engineering: a practitioner's approach. Palgrave macmillan.

Sholih, F. B. (2014). Perancangan Aplikasi Penjualan Batik Berbasis Android (Studi Kasus di Batik Puspa Kencana, Laweyan, Solo) (Doctoral dissertation, Universitas Muhammadiyah Surakarta).

Betha, S. (2012). Pemrograman web dengan php. Bandung: Informatika.

Tambunan, D. D. (2017). Analisis Yuridis Undang-Undang No. 20 Tahun 2008 Tentang Usaha Mikro, Kecil, Dan Menengah Terkait Persaingan Usaha Terhadap Keadilan Sosial (Social Equity) Bagi Pelaku Usaha (Doctoral dissertation, UAJY).

Rifa'i, M., Listyorini, T., \& Latubessy, A. (2014). Penerapan Teknologi Augmented Reality pada aplikasi katalog rumah berbasis android. Prosiding SNATIF, 267-274.

Winardi, J. (2005). Manajemen perubahan. Jakarta: Prenada Media. 